\title{
How to deal with patients with atrial fibrillation during an epidemic?
}

\author{
Anna Tomaszuk-Kazberuk
}

Department of Cardiology, Medical University of Białystok, Białystok, Poland

\begin{abstract}
Patients with atrial fibrillation (AF) due to old age and comorbidities are at a higher risk of SARS-CoV-2 infection. These patients should protect themselves by limiting contact with other people to an absolute minimum and they should be educated about hygiene, including careful hand washing. In general, the principles of antiarrhythmic drug treatment of quarantined, infected and asymptomatic individuals remain unchanged. In the hospital setting it is important to remember about possible interactions between anticoagulants, antibiotics, antiarrhythmic, antiviral and antimalarial drugs. The current pandemic also led to limitations regarding the implantation and control of implantable devices to an absolute minimum.
\end{abstract}

Keywords: atrial fibrillation - coronavirus - infection - SARS-CoV-2 Severe Acute Respiratory Syndrome Coronavirus-2 · COVID-19 • Coronavirus disease $2019 \cdot$ non-vitamin K oral anticoagulants (NOACs)

\section{Citation}

Tomaszuk-Kazberuk A. How to deal with patients with atrial fibrillation during an epidemic?. Eur J Transl Clin Med. 2020;3(1):53-59.

DOI: $10.31373 /$ ejtcm/120487

\section{Introduction}

In March of this year the World Health Organization (WHO) announced that the current global coronavirus-related situation (coronavirus disease 2019, COVID-19) is a pandemic. The causative agent the severe acute respiratory syndrome coronavirus 2 (SARS-CoV-2) belongs to the highly pathogenic $\beta$-co- ronavirus family. Besides pneumonia, SARS-CoV-2 may cause severe respiratory disorders [1-2]. This virus spreads via droplets and through direct contact with an infected person. The cases of spreading the virus by air have not been confirmed and although it is not considered significant, it cannot be ignored when medical procedures involving the formation of aerosol are carried out [3]. The conjunctiva of the eye

Corresponding author:

Anna Tomaszuk-Kazberuk, Department of Cardiology, Medical University of Białystok, Białystok, Poland

e-mail: a.tomaszuk@poczta.fm

No external funds.

Available online: www.ejtcm.gumed.edu.pl

Copyright ${ }^{\circledR}$ Medical University of Gdańsk

This is Open Access article distributed under the terms of the Creative Commons Attribution-ShareAlike 4.0 International. 
is also very likely to be infected due to fluid contamination. The virus incubation period is on average 4-5 days. According to data published by the WHO, the time to onset of symptoms is usually 5 days and no later than 11.5 days [4].

A positive epidemiological history is an important step in the diagnosis of SARS-CoV-2 infection. The epidemiological factors in the period of 2 weeks preceding the onset of the disease are: a visit to an area where the disease occurs, contact with a COVID19-positive person or contact with a symptomatic person (e.g. fever and respiratory symptoms) from the area where the infection occurs.

Clinically the infection presents primarily with fever and/or respiratory symptoms. Radiological signs in computer tomography of the lungs are frequent. Whereas laboratory tests may reveal normal or decreased white blood cell count or decreased lymphocyte count [5].

\section{Material and methods}

This is a narrative-type review of current English-language literature on the subject of COVID-19 and atrial fibrillation. No statistical analysis was performed.

\section{Results}

\section{What is known so far about COVID-19} and cardiovascular diseases?

Infection of SARS-CoV-2 is caused by binding of the viral spike protein to the human angiotensin-converting enzyme 2 (ACE2) receptor. The binding is followed by an activation of the viral spike protein by transmembrane protease serine 2 (TMPRSS2) [6].

ACE2 receptor is expressed in the lung and is the predominant way of entry. ACE2 is expressed also in the heart. ACE2 receptor as well is expressed in the intestinal epithelium, vascular endothelium, and the kidneys. This explains the multi-organ dysfunction occurrence in SARS-CoV-2 infection [7]. Unfortunately, there is increasing evidence showing that COVID-19 is connected with increased morbidity and mortality in patients with cardiovascular diseases.

The case fatality rate (CFR, number of deaths/ number of those diagnosed) is a very important parameter. In patients with no comorbidities the CFR is $0.9 \%$, whereas in patients with cardiovascular disease (CVD) it is increased to $10.5 \%$. For patients with diabetes mellitus (DM) the CFR is $7.3 \%$, while $6.3 \%$ for chronic obstructive pulmonary disease, $6 \%$ for hypertension (HTN) and 5.6\% for cancer [8].
Recent meta-analysis of eight studies from China including 46,248 infected patients showed the most prevalent commodities were HTN $(17 \pm 7 \%, 95 \% \mathrm{Cl}$ $14-22 \%)$ and DM $(8 \pm 6 \%, 95 \% \mathrm{Cl} 6-11 \%)$, followed by cardiovascular diseases ( $5 \pm 4 \%, 95 \% \mathrm{Cl} 4-7 \%$ ) [9]. Myocardial injury in COVID-19 was proved by elevated cardiac biomarkers. In the Chinese study of 138 hospitalized patients with COVID-19 in Wuhan elevated high sensitivity troponin I [hs-cTnl] or new ECG or echocardiographic abnormalities were present in $7.2 \%$ of patients overall, and $22 \%$ that required treatment at an intensive care unit [10].

The report from the National Health Commission (NHC) of China comments that there is a subset of COVID-19 patients who presented with palpitations and chest pain, not the typical fever and cough [11]. Based on limited data, it seems that the incidence of fulminant myocarditis and cardiogenic shock is low [12].

\section{Problems with INR assessment}

In March 2020 a substantial number of laboratories in Poland were either closed or had limited working hours. This way the access to INR assessment became limited. In such circumstances it is advisable to switch from vitamin $\mathrm{K}$ antagonists to NOACs whenever it is possible, except for patients with artificial heart valves, recent implantation of biological valves, rheumatic stenosis or anti-phospholipid syndrome.

It is noteworthy that patients on NOAC cannot be deprived of the assessment of kidney function parameters. The test of choice is Creatinine Clearance $(\mathrm{CrCl})$ calculated using the Cockroft-Gault equation. Patients taking NOACs need to have a renal function test at least annually in order to modify the dose if needed. If the patient's renal function is impaired (i.e. $\mathrm{CrCl} \leq 60 \mathrm{~mL} / \mathrm{min}$ ), a more frequent evaluation is recommended. The minimum frequency of renal function testing (in months) can be obtained by simply dividing the patient's recent $\mathrm{CrCl}$ by 10 . In patients with additional risk factors (e.g. older age, frail, multiple comorbidities etc.), renal function may be evaluated even more frequently [13].

\section{Is there any interaction between COVID-19 virus and NOAC?}

If the patient with AF on NOAC is experiencing symptoms of COVID-19 or is suspect that may be infected with COVID-19, it is advised to consult with healthcare provider and closely follow the treatment recommendations that are given. 
Depending on individual symptoms and medical history, if a patient with AF treated with NOAC is infected with COVID-19, the healthcare provider should advise if and exactly how the treatment needs to be adjusted. Until then, the patient should continue the treatment with NOAC as previously advised by the healthcare provider.

\section{Is there any interaction between NOACs and antimalarials or antivirals?}

No detailed information is available yet for many potential interactions with NOACs and drugs that are used in AF patients. NOAC producers have not conducted dedicated drug-drug interaction studies to evaluate the co-administration of NOACs and the drugs listed above. For example, the recommendation listed in the manufacturer's label for dabigatran is based on the only drug-drug interaction study conducted with ritonavir, regarding its use in the treatment of human immunodeficiency virus (HIV) [13]. Concomitant use with protease inhibitors such as ritonavir (and its combination with other protease inhibitors for example lopinavir) is not recommended. These drugs affect $P$ glycoprotein (P-gp). As specified on the label, the pro-drug dabigatran etexilate but not dabigatran is a substrate of the transporter $\mathrm{P}$ glycoprotein (P-gp) [14].

P-gp inhibitors may increase exposure to dabigatran and therefore may increase the risk of bleeding. Close clinical monitoring for signs of bleeding or anemia and dose reductions may be required. P-gp inducers are expected to reduce dabigatran systemic exposure. Co-administration of potent P-gp inducers with dabigatran should be avoided.

Neither dabigatran etexilate nor its active metabolite dabigatran are metabolized by the cytochrome P450 system or have an effect on in vitro cytochrome P450 enzymes. Dabigatran is not expected to have any cytochrome $\mathrm{P} 450$ related drug-drug interactions.

No dedicated studies with antiretroviral medications such as Darunavir + cobicistat used in HIV infection and NOACs have been conducted as dedicated drug-drug interaction studies. Darunavir and cobicistat are both P-gp inhibitors. Coadministration of darunavir and cobicistat with dabigatran may result in increased dabigatran exposure and increased risk of bleeding [15].

According to dabigatran label, concomitant treatment with strong P-gp inhibitors is contraindicated. If not otherwise specifically described, close clinical surveillance (looking for signs of bleeding or anaemia), dose reductions may be required [14].

No relevant literature citations were identified in MEDLINE and EMBASE with the search terms "dabigatran" and the antimalarial or antiviral drugs such as: "chloroquine phosphate," "hydroxychloroquine" and "oseltamivir." Furthermore, no results were found for "dabigatran" and "remdesivir," "camostat," "favilavir" or "favipiravir." As always, clinical judgment should be crucial in managing every individual patient. Apixaban, rivaroxaban and dabigatran should not be used with atazanavir and lopinavir/ritonavir (see Table 1).

Table 1. Interactions of anti-coagulant, anti-platelet and fibrinolytic drugs with antimalarial and antiviral drugs used in experimental treatment of COVID-19

\begin{tabular}{|c|c|c|c|c|c|c|c|c|c|}
\hline & ATV & $\mathrm{LPV} / \mathrm{r}$ & RDV & FAVI & CLQ & HCLQ & RBV & TCZ & IF $N-\boldsymbol{\beta}$ \\
\hline Apixaban & & & $\leftrightarrow$ & $\leftrightarrow$ & & 个 & $\leftrightarrow$ & $\downarrow$ & $\leftrightarrow$ \\
\hline Aspirin (anti-platelet) & $\leftrightarrow$ & $\leftrightarrow$ & $\leftrightarrow$ & $\leftrightarrow$ & $\leftrightarrow$ & $\leftrightarrow$ & $\leftrightarrow$ & $\leftrightarrow$ & $\leftrightarrow$ \\
\hline Betrixaban & & & $\leftrightarrow$ & $\leftrightarrow$ & & $\uparrow$ & $\leftrightarrow$ & $\leftrightarrow$ & $\leftrightarrow$ \\
\hline Clopidogrel & & , & $\leftrightarrow$ & $\leftrightarrow$ & $\leftrightarrow$ & $\leftrightarrow$ & $\leftrightarrow$ & $\downarrow$ & $\leftrightarrow$ \\
\hline
\end{tabular}




\begin{tabular}{|c|c|c|c|c|c|c|c|c|c|}
\hline Dalteparin & $\leftrightarrow$ & $\leftrightarrow$ & $\leftrightarrow$ & $\leftrightarrow$ & $\leftrightarrow$ & $\leftrightarrow$ & $\leftrightarrow$ & $\leftrightarrow$ & $\leftrightarrow$ \\
\hline Dipyridamole & $\uparrow$ & $\downarrow$ & $\leftrightarrow$ & $\leftrightarrow$ & $\leftrightarrow$ & $\leftrightarrow$ & $\leftrightarrow$ & $\leftrightarrow$ & $\leftrightarrow$ \\
\hline Edoxaban & $\uparrow$ & $\uparrow$ & $\leftrightarrow$ & $\leftrightarrow$ & $\uparrow$ & $\uparrow$ & $\leftrightarrow$ & $\leftrightarrow$ & $\leftrightarrow$ \\
\hline Enoxaparin & $\leftrightarrow$ & $\leftrightarrow$ & $\leftrightarrow$ & $\leftrightarrow$ & $\leftrightarrow$ & $\leftrightarrow$ & $\leftrightarrow$ & $\leftrightarrow$ & $\leftrightarrow$ \\
\hline Fondaparinux & $\leftrightarrow$ & $\leftrightarrow$ & $\leftrightarrow$ & $\leftrightarrow$ & $\leftrightarrow$ & $\leftrightarrow$ & $\leftrightarrow$ & $\leftrightarrow$ & $\leftrightarrow$ \\
\hline Heparin & $\leftrightarrow$ & $\leftrightarrow$ & $\leftrightarrow$ & $\leftrightarrow$ & $\leftrightarrow$ & $\leftrightarrow$ & $\leftrightarrow$ & $\leftrightarrow$ & $\leftrightarrow$ \\
\hline Phenprocoumon & $\uparrow$ & $\uparrow \downarrow$ & $\leftrightarrow$ & $\leftrightarrow$ & $\leftrightarrow$ & $\leftrightarrow$ & $\leftrightarrow$ & $\downarrow$ & $\leftrightarrow$ \\
\hline Prasugel & $\leftrightarrow$ & $\leftrightarrow$ & $\leftrightarrow$ & $\leftrightarrow$ & $\leftrightarrow$ & $\leftrightarrow$ & $\leftrightarrow$ & $\downarrow$ & $\leftrightarrow$ \\
\hline Rivaroxaban & $\uparrow$ & $\uparrow$ & $\leftrightarrow$ & $\leftrightarrow$ & $\uparrow$ & $\uparrow$ & $\leftrightarrow$ & $\downarrow$ & $\leftrightarrow$ \\
\hline Streptokinase & $\leftrightarrow$ & $\leftrightarrow$ & $\leftrightarrow$ & $\leftrightarrow$ & $\leftrightarrow$ & $\leftrightarrow$ & $\leftrightarrow$ & $\leftrightarrow$ & $\leftrightarrow$ \\
\hline Ticagrelor & $\uparrow$ & $\uparrow$ & $\leftrightarrow$ & $\leftrightarrow$ & $\leftrightarrow$ & $\leftrightarrow$ & $\leftrightarrow$ & $\downarrow$ & $\leftrightarrow$ \\
\hline Warfarin & $\uparrow$ & $\downarrow$ & $\leftrightarrow$ & $\leftrightarrow$ & $\leftrightarrow$ & $\leftrightarrow$ & $\downarrow$ & $\downarrow$ & $\leftrightarrow$ \\
\hline
\end{tabular}

Abbreviations: ATV - Atazanavir; LPV/r - Lopinavir/ritonavir; RDV - Remdesivir; FAVI - Favipiravir; CLQ - Chloroquine; HCLQ - Chydroxycloroquine; RBV - Ribavirin; TCZ - Tocilizumab; IFN- $\beta$ - Interferon beta

\section{Color legend}

These drugs should not be coadministered

Potential interaction which may require a dose adjustment or close monitoring

Potenttial interaction likely to be weak intensity.

Additional action/monitoring or dosage adjustment unlikely to be required

No clinically significant interaction expected

Detailed recommendations for about drug interactions with experimental COVID-19

therapies are updated regularly at: http://www.covid19-druginteractions.org/

\section{Text legend}

个 Potential increased exposure of the comedication

$\downarrow$ Potential decreased exposure

$\downarrow$ of the comedication

$\leftrightarrow \quad$ No significant effect

One or both drugs may cause QT and/or PR prolongation. ECG monitoring is advised if coadministered

\section{Is there any interaction between NOACs and tocilizumab (IL6-receptor blocker)?}

The manufacturers of NOACs have not conducted dedicated drug-drug interaction studies to evaluate the coadministration of NOACs and tocilizumab. According to European Medicines Agency's summary of product characteristics, tocilizumab interacts with cytochrome 450, no information on drug-drug interaction related to P-gp transport is available [16]. According to dabi- gatran label, dabigatran is not expected to have any cytochrome $\mathrm{P} 450$ related drug-drug interactions [17].

\section{Are there any interactions between experimental COVID-19 therapies and azithromycin?}

Prolonged cardiac repolarization and QT interval, imparting a risk of lethal ventricular arrhythmias including torsades de pointes, were observed in treatment 
with macrolide antibiotics including azithromycin Therefore, azithromycin should be used with caution in patients with ongoing proarrhythmic conditions (especially women and elderly patients) such as:

- current treatment with other known QT interval-prolonging drugs such as class IA (quinidine and procainamide) and class III (dofetilide, amiodarone and sotalol) antiarrhythmics,

- electrolyte abnormalities, particularly hypokalaemia and hypomagnesaemia,

- clinically-relevant bradycardia, cardiac arrhythmia or severe cardiac insufficiency.
Some observational studies have identified a rare short term risk of arrhythmia, myocardial infarction and cardiovascular mortality associated with macrolides including azithromycin. Consideration of these findings should be balanced with treatment benefits when prescribing azithromycin [18].

\section{Are there any interactions between experimental COVID-19 therapies and antiarrhythmics?}

See Table 2.

Table 2. Interactions of antiarrhythmic drugs with antimalarial and antiviral drugs used in experimental treatment of COVID-19

\begin{tabular}{|c|c|c|c|c|c|c|c|c|c|}
\hline & ATV & $\mathbf{L P V} / \mathbf{r}$ & RDV & FAVI & CLQ & HCLQ & RBV & TCZ & IFN- $\boldsymbol{\beta}$ \\
\hline Amiodarone & & & $\leftrightarrow$ & $\leftrightarrow$ & & $\bullet$ & $\leftrightarrow$ & $\downarrow$ & $\leftrightarrow$ \\
\hline Bepridil & & & $\leftrightarrow$ & $\leftrightarrow$ & & $\uparrow \bullet$ & $\leftrightarrow$ & $\leftrightarrow$ & $\leftrightarrow$ \\
\hline Disopyramide & & & $\leftrightarrow$ & $\leftrightarrow$ & $\leftrightarrow \bullet$ & $\leftrightarrow \bullet$ & $\leftrightarrow$ & $\leftrightarrow$ & $\leftrightarrow$ \\
\hline Dofetilide & & & $\leftrightarrow$ & $\leftrightarrow$ & $\leftrightarrow \bullet$ & $\leftrightarrow \bullet$ & $\leftrightarrow$ & $\leftrightarrow$ & $\leftrightarrow$ \\
\hline Flecainide & & & $\leftrightarrow$ & $\leftrightarrow$ & & & $\leftrightarrow$ & $\leftrightarrow$ & $\leftrightarrow$ \\
\hline Lidocaine (Lignocaine) & 个 & $\uparrow$ & $\leftrightarrow$ & $\leftrightarrow$ & $\leftrightarrow$ & $\leftrightarrow$ & $\leftrightarrow$ & $\leftrightarrow$ & $\leftrightarrow$ \\
\hline Mexiletine & $\leftrightarrow$ & $\uparrow$ & $\leftrightarrow$ & $\leftrightarrow$ & & $\uparrow \bullet$ & $\leftrightarrow$ & $\leftrightarrow$ & $\leftrightarrow$ \\
\hline Propafenone & $\uparrow$ & $\uparrow$ & $\leftrightarrow$ & $\leftrightarrow$ & $\leftrightarrow \bullet$ & $\leftrightarrow \boldsymbol{\bullet}$ & $\leftrightarrow$ & $\leftrightarrow$ & $\leftrightarrow$ \\
\hline Quinidine & $\uparrow$ & $\uparrow$ & $\leftrightarrow$ & $\leftrightarrow$ & $\leftrightarrow \boldsymbol{v}$ & $\leftrightarrow \boldsymbol{\varphi}$ & $\leftrightarrow$ & $\downarrow$ & $\leftrightarrow$ \\
\hline
\end{tabular}

Abbreviations: ATV - Atazanavir; LPV/r - Lopinavir/ritonavir; RDV - Remdesivir; FAVI - Favipiravir; CLQ - Chloroquine; HCLQ - Chydroxycloroquine; RBV - Ribavirin; TCZ - Tocilizumab; IFN- $\beta$ - Interferon beta

\section{Color legend}

These drugs should not be coadministered

Potential interaction which may require a dose adjustment or close monitoring Potenttial interaction likely to be weak intensity. Additional action/monitoring or dosage adjustment unlikely to be required

$\square$ No clinically significant interaction expected

Detailed recommendations for about drug interactions with experimental COVID-19 therapies are updated regularly at: http://www.covid19-druginteractions.org/

\section{Text legend}

个 Potential increased exposure of the comedication

$\downarrow$ Potential decreased exposure of the comedication

$\leftrightarrow \quad$ No significant effect

One or both drugs may cause QT and/ or PR prolongation. ECG monitoring is advised if coadministered 


\section{Indications for electrotherapy and electrophysiology procedures during the pandemic}

For patients from the general population (people without confirmed infection and with a negative history of risk factors for infection), it seems reasonable to postpone elective procedures such as:

- elective ablation of atrial fibrillation,

- implantation of cardiac pacemaker in case of tachycardia-bradycardia syndrome (atrial fibrillation as tachycardia) with scant symptoms.

The purpose of this restriction is to protect patients from contact with healthcare professionals and healthcare facilities, where the risk of infection is higher. Replacement of pacing systems due to a depleted battery or damaged electrodes should be carried out according to previously used procedures.

If possible, for people with suspected COVID-19 infection (people in quarantine awaiting their COVID-19 test result and with a history indicating the possibility of infection), the procedures should be postponed in all cases until confirmation or exclusion of infection.

Whereas for patients with a confirmed diagnosis of COVID-19 procedures should be carried out only if the patient has a life-threatening condition and performed in infectious disease hospitals with an electrotherapy laboratory. Otherwise, if the patient is not in a life-threatening condition, then the procedure should be postponed until the patient is cured of the COVID-19 infection or until the pandemic is over.

Postoperative pacemaker control, radiological and echocardiographic control, if possible, should be postponed until the patient's epidemiological status is confirmed. If this is not possible, the procedures should be carried out in accordance with the center's internal procedures adopted for the care of patients with COVID-19 [19].

Prior to a planned device control visit, it is recom- mended to make telephone contact with the patient or caregiver and to history regarding clinical events (fainting, loss of consciousness) and disturbing symptoms associated with the device placement (e.g. redness, swelling, soreness, thinning of the skin) which may indicate a local infection or perforation. When in doubt, it is recommended that the patient sends photographs of suspicious changes for verification by the supervising cardiologist.

When using telemedicine systems for implantable devices that do not use daily automatic transmissions, the date and time of the planned data transmission from the implanted device should be set.

In each case, the date of the control visit and patient transportation should be agreed upon with the supervising cardiologist (or with other staff at the clinic). The patient should not use public transportation to and from the control visit. The patient should be advised to arrive on time and if possible use personal protective equipment (mask, gloves). The clinic staff should organize the process of registration and admission of the patient in way that minimizes the number of people in direct contact with the patient [20].

\section{Conclusions}

Patients with atrial fibrillation (AF) due to old age and comorbidities are at a higher risk of severe COVID-1 cours infection. These patients should protect themselves by limiting contact with other people to an absolute minimum and they should be educated about hygiene, including careful hand washing. In general, the principles of antiarrhythmic drug treatment of quarantined, infected and asymptomatic individuals remain unchanged. In the hospital setting it is important to remember about possible interactions between anticoagulants, antibiotics, antiarrhythmic, antiviral and antimalarial drugs. The current pandemic also led to limitations regarding the implantation and control of implantable devices to an absolute minimum.

\section{References}

1. Huang C, Wang Y, Li X, Ren L, Zhao J, Hu Y, et al. Clinical features of patients infected with 2019 novel coronavirus in Wuhan, China. Lancet [Internet]. 2020 Feb;395(10223):497-506. Available from: https://doi.org/10.1016/S01406736(20)30183-5

2. Wu F, Zhao S, Yu B, Chen Y-M, Wang W, Song Z-G, et al. A new coronavirus associated with human respiratory disease in China. Nature [Internet]. 2020 Mar 3;579(7798):265-9. Available from: https://doi.org/10.1038/s41586-020-2008-3

3. Report of the who-china joint mission on coronavirus disease 2019 (covid-19) [Internet]. 2020. Available from: https:// www.who.int/docs/default-source/coronaviruse/who-china-joint-mission-on-covid-19-final-report.pdf 
4. World Health Organization. Q\&A on coronaviruses (COVID-19) [Internet]. 2020 [cited 2020 Apr 14]. Available from: https://www.who.int/news-room/q-a-detail/q-a-coronaviruses

5. Wujtewicz M, Dylczyk-Sommer A, Aszkiełowicz A, Zdanowski S, Piwowarczyk S, Owczuk R. COVID-19 - what should anaethesiologists and intensivists know about it? Anaesthesiol Intensive Ther [Internet]. 2020;52(1):34-41. Available from: https://doi.org/10.5114/ait.2020.93756

6. Hoffmann M, Kleine-Weber H, Schroeder S, Krüger N, Herrler T, Erichsen S, et al. SARS-CoV-2 Cell Entry Depends on ACE2 and TMPRSS2 and Is Blocked by a Clinically Proven Protease Inhibitor. Cell. 2020 Mar 5; [in press].

7. Zhang H, Penninger JM, Li Y, Zhong N, Slutsky AS. Angiotensin-converting enzyme 2 (ACE2) as a SARS-CoV-2 receptor: molecular mechanisms and potential therapeutic target. Intensive Care Med [Internet]. 2020 Apr 3;46(4):586-90. Available from: https://doi.org/10.1007/s00134-020-05985-9

8. Wu Z, McGoogan JM. Characteristics of and Important Lessons From the Coronavirus Disease 2019 (COVID-19) Outbreak in China. JAMA [Internet]. 2020 Apr 7;323(13):1239. Available from: https://doi.org/10.1001/iama.2020.2648

9. Yang J, Zheng Y, Gou X, Pu K, Chen Z, Guo Q, et al. Prevalence of comorbidities in the novel Wuhan coronavirus (COVID-19) infection: a systematic review and meta-analysis. Int J Infect Dis. 2020 Mar; [in press].

10. Wang D, Hu B, Hu C, Zhu F, Liu X, Zhang J, et al. Clinical Characteristics of 138 Hospitalized Patients With 2019 Novel Coronavirus-Infected Pneumonia in Wuhan, China. JAMA [Internet]. 2020 Mar 17;323(11):1061. Available from: https:// jamanetwork.com/journals/jama/fullarticle/2761044

11. Zheng Y-Y, Ma Y-T, Zhang J-Y, Xie X. COVID-19 and the cardiovascular system. Nat Rev Cardiol [Internet]. 2020 Mar 5; Available from: http://www.nature.com/articles/s41569-020-0360-5

12. Clerkin KJ, Fried JA, Raikhelkar J, Sayer G, Griffin JM, Masoumi A, et al. Coronavirus Disease 2019 (COVID-19) and Cardiovascular Disease. Circulation [Internet]. 2020 Mar 21;CIRCULATIONAHA.120.046941. Available from: https://www. ahajournals.org/doi/10.1161/CIRCULATIONAHA.120.046941

13. Kumar P, Gordon LA, Brooks KM, George JM, Kellogg A, McManus M, et al. Differential Influence of the Antiretroviral Pharmacokinetic Enhancers Ritonavir and Cobicistat on Intestinal P-Glycoprotein Transport and the Pharmacokinetic/ Pharmacodynamic Disposition of Dabigatran. Antimicrob Agents Chemother [Internet]. 2017 Nov 1;61(11):e01201-17. Available from: http://aac.asm.org/content/61/11/e01201-17.abstract

14. Pradaxa. Summary of Product Characteristics. European Medicines Agency [Internet]. [cited 2020 Apr 14]. Available from: https://www.ema.europa.eu/en/documents/product-information/pradaxa-epar-product-information_en.pdf

15. Steffel J, Verhamme P, Potpara TS, Albaladejo P, Antz M, Desteghe L, et al. The 2018 European Heart Rhythm Association Practical Guide on the use of non-vitamin K antagonist oral anticoagulants in patients with atrial fibrillation. Eur Heart J [Internet]. 2018;39(16):1330-93. Available from: https://doi.org/10.1093/eurheartj/ehy136

16. RoActemra. Summary of Product Characteristics. European Medicines Agency [Internet]. [cited 2020 Apr 14]. Available from: https://www.ema.europa.eu/en/documents/product-information/roactemra-epar-product-information en.pdf

17. Interactions with Experimental COVID-19 Therapies. The Liverpool Drug Interaction Group (University of Liverpool, UK), University Hospital of Basel (Switzerland) and Radboud UMC (Netherlands). [Internet]. [cited 2020 Apr 14]. Available from: http://www.covid19-druginteractions.org

18. Azithromycin. Summary of Product Characteristics [Internet]. [cited 2020 Apr 14]. Available from: http://products.tevauk.com/mediafile/id/47493.pdf

19. Komunikat Sekcji Rytmu Serca Polskiego Towarzystwa Kardiologicznego dotyczący trybu i sposobu wykonywania zabiegów z zakresu elektroterapii lub elektrofizjologii serca w okresie epidemii COVID-19. [Internet]. [cited 2020 Apr 14]. Available from: http://www.rytmserca.ptkardio.pl/news/188-komunikat sekcji rytmu serca polskiego towarzystwa kardiologicznego dotyczacy trybu i sposobu przeprowadzania kontroli elektronicznych urzadzen wszczepialnych cied $w$ okresie epidemii covid19

20. Komunikat Sekcji Rytmu Serca Polskiego Towarzystwa Kardiologicznego dotyczący trybu i sposobu przeprowadzania kontroli Elektronicznych Urządzeń Wszczepialnych (CIED) w okresie epidemii COVID-19 [Internet]. [cited 2020 Apr 14]. Available from: http://www.rytmserca.ptkardio.pl/news/188-komunikat sekcji rytmu serca polskiego towarzystwa kardiologicznego dotyczacy trybu i sposobu przeprowadzania kontroli elektronicznych urzadzen wszczepialnych cied $\mathrm{w}$ okresie epidemii covid19 